\title{
Neonatal tetralogy of Fallot with doubly committed ventricular septal defect and severe pulmonary valvar stenosis: A contraindication for catheter intervention?
}

\author{
Martin Kostolny, MD, ${ }^{a}$ Victor T. Tsang, MD, FRCS, ${ }^{a}$ Jan Marek, MD, ${ }^{a}$ Graham Derrick, MD, ${ }^{a}$ and

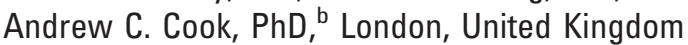

\begin{abstract}
Balloon dilation of the pulmonary valve is regarded as the treatment of choice for isolated pulmonary valvar stenosis. This technique can also be performed palliatively, delaying surgical treatment in neonates with tetralogy of Fallot (TOF) and severe pulmonary valvar stenosis. ${ }^{1}$ We report a case of TOF and a doubly committed ventricular septal defect (VSD) in which pulmonary valvar stenosis was balloon dilated. This led to the rupture of the adjacent aortic sinus wall and development of significant aortic regurgitation.
\end{abstract}

\section{Clinical Summary}

The patient presented in the neonatal period with TOF, a doubly committed subarterial VSD, and predominantly pulmonary valvar stenosis. In view of the patient's low weight $(2.2 \mathrm{~kg})$ and episodes of desaturation to $40 \%$ in air, a palliative balloon pulmonary valvotomy was considered to allow growth before a definitive repair.

A balloon pulmonary valvotomy was performed using a 7-mm Tyshak II (NuMED Inc., Hopkinton, NY) balloon. Oxygen saturation improved, and the echocardiographic Doppler velocity across the pulmonary valve was $3 \mathrm{~m} / \mathrm{s}$. However, low systemic arterial diastolic pressures became apparent soon after the balloon dilatation, and severe aortic regurgitation was demonstrated, with the regurgitation jet directed toward the right ventricle (Figure 1, A).

At surgery, a longitudinal tear was discovered in the wall of the right coronary sinus of the aortic root (Figure 1,B). The aortic defect was closed with interrupted sutures. At the same time, complete repair was performed with patch closure of the VSD, and relief of right ventricular outflow tract obstruction was performed with a transannular patch.

The patient was discharged 6 days after surgery and was shown to have a competent aortic valve and no residual VSD with good biventricular function on echocardiography at 6 months follow-up.

From the Cardiothoracic Unit, ${ }^{\text {a }}$ Great Ormond Street Hospital, and National Health Service Trust and Institute for Child Health at the University College London, ${ }^{\mathrm{b}}$ London, United Kingdom.

Received for publication March 13, 2007; accepted for publication March 20, 2007.

Address for reprints: Martin Kostolny, MD, Cardiothoracic Unit, Great Ormond Street Hospital, Great Ormond Street, WC1N 3JH, London, UK (E-mail: kostom@gosh.nhs.uk).

J Thorac Cardiovasc Surg 2007;134:258-9

$0022-5223 / \$ 32.00$

Copyright @ 2007 by The American Association for Thoracic Surgery doi:10.1016/j.jtcvs.2007.03.031

\section{Discussion}

Our experience highlights the importance of taking the salient morphology into consideration when determining the surgical and interventional options for treatment of congenital cardiac malformations. The phenotypic feature of the doubly committed defect is the absence of the muscular outlet septum; this represents the posterior aspect of the free-standing muscular subpulmonary infundibulum of the normal heart (Figure 2). The failure of formation of these muscular structures causes the facing leaflets of the aortic and pulmonary valves to be in fibrous continuity, producing the fibrous raphe that forms the superior rim of the defect. ${ }^{2}$

In our patient, the dilation performed with a balloon resulted in splitting the fused posterior end of the zone of apposition between the leaflets of the bicuspid pulmonary valve. Because of the fibrous continuity between these leaflets and those of the aortic valve, reflecting the doubly committed nature of the VSD, the procedure also created a tear in the wall of the adjacent aortic valvar sinus. Consequently, in diastole, there was massive regurgitation toward the right ventricular outflow tract.

Although balloon dilatation is commonly accepted as the definitive and palliative procedure for pulmonary valvar stenosis, there are no published reports of balloon dilatation of the stenosed pulmonary valve in doubly committed subarterial VSD. During balloon dilatation of simple pulmonary valvar stenosis, it is generally accepted to choose a balloon dimension of $125 \%$ of the dimension of the pulmonary valve. ${ }^{3}$ Larger balloons are associated with greater complication rates and pulmonary valve regurgitation. In doubly committed VSD, with the fibrous continuity between the aortic and the pulmonary valves, a much more cautious approach was adopted. The pulmonary valve was $8 \mathrm{~mm}$, and a conservative 7-mm balloon was chosen. Yet, major trauma to the adjacent aortic sinus wall occurred, requiring urgent surgery.

\section{Conclusion}

We present a case of iatrogenic aortic regurgitation in a patient with TOF and doubly committed VSD. For the reasons outlined, balloon dilation of the pulmonary valve should be avoided in this morphologic setting.

\section{References}

1. Garty Y, Veldtman G, Lee K, Benson L. Late outcomes after pulmonary valve balloon dilatation in neonates, infants and children. $J$ Invasive Cardiol. 2005;17:318-22.

2. Wilcox BR, Cook AC, Anderson RH. Lesions with normal segmental connections: In: Wilcox BR, Cook AC, Anderson RH, eds. Surgical Anatomy of the Heart. 3rd edition. Cambridge, UK: Cambridge University Press; 2004:169.

3. Rao PS. Balloon pulmonary valvuloplasty in children. $J$ Invasive Cardiol. 2005;17:323-5. 


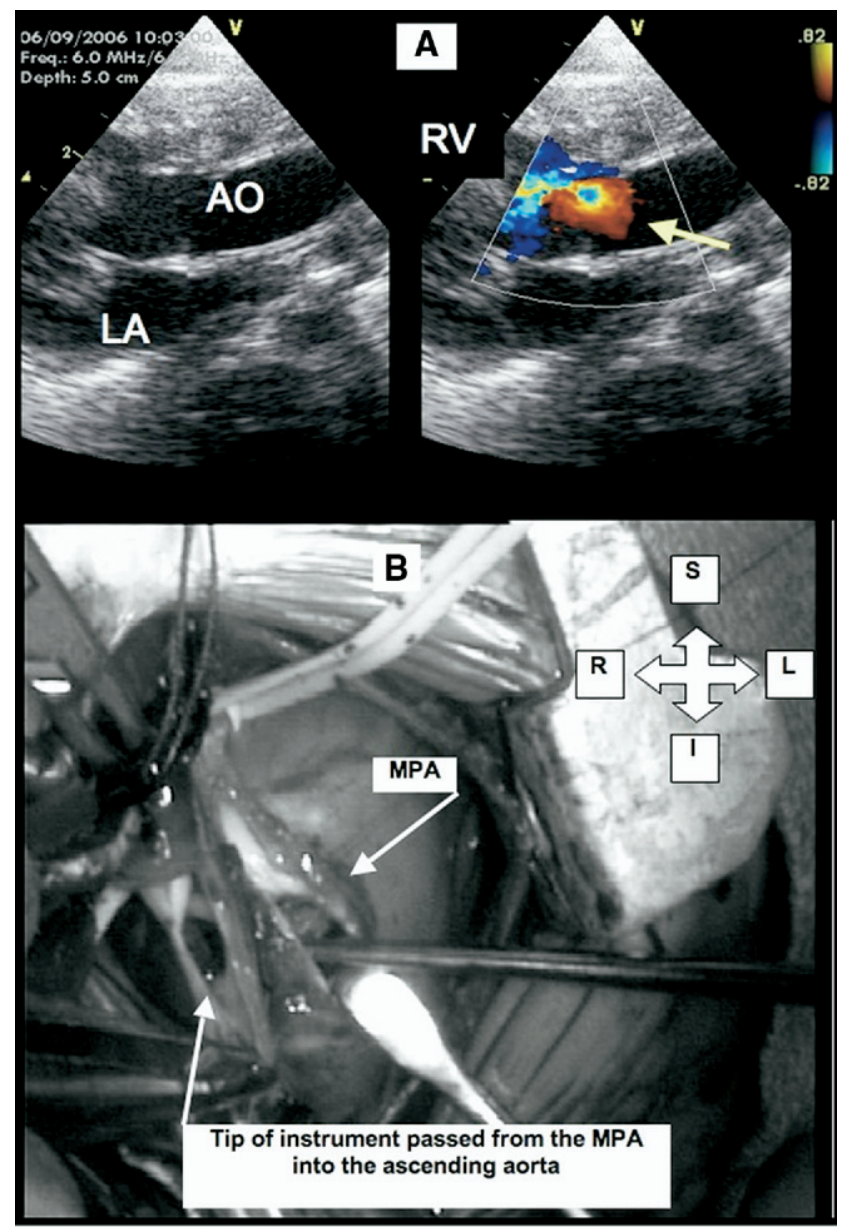

Figure 1. On echocardiography, the aortic regurgitation can be seen in parasternal long-axis views (A). Surgical view (B). AO, Aorta; $L A$, left atrium; $R V$, right ventricle; $M P A$, main pulmonary artery; $S$, superior; $I$, inferior; $L$, left; $R$, right.

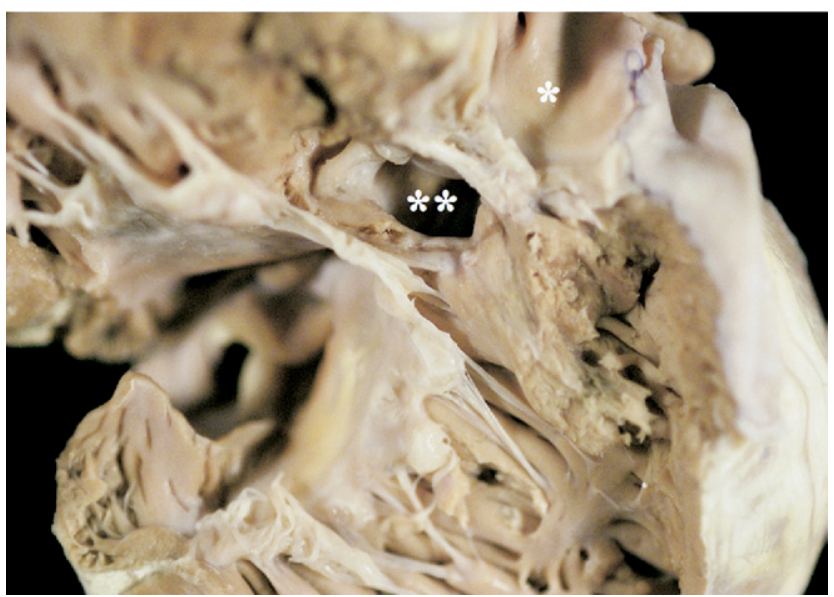

Figure 2. Pathologic specimen of a heart with TOF and a doubly committed VSD from the Specimen Archives at the Great Ormond Street Hospital, National Health Service Trust. The fibrous continuity of both aortic and pulmonary valves is demonstrated. *Pulmonary valve. **Aortic valve seen through the VSD. TOF, tetralogy of fallot; VSD, ventricular septal defect. 